ICRDET-2021, February 26-27, 2021, AICE, Jaipur, India

International Journal of Technical Research \& Science (Special Issue) ISSN No.:2454-2024 (online)

\title{
HARMONICS MITIGATION USING HYBRID FILTER
}

\author{
Ajit Yadav, Vishal Yadav \\ E-Mail Id: ajit@anandice.ac.in, vishalyadavhw9544@gmail.com \\ Department of Electrical engineering, Anand International College of Engineering, Jaipur, Rajasthan \\ (India)
}

Abstract- Nowadays with the advancement of technology, the demand for electrical power is increasing at an exponential rate. Many consumer appliances demand consistent quality power for their operation. The performance of the end-user equipment depends heavily on the quality of power supplied to it. But the quality of power delivered to the end-user is affected by various external and internal factors such as voltage and frequency variations, faults, outages, etc. These power quality problems reduce the lifespan and efficiency of the equipment. Thus, these problems should be minimized to enhance the performance of the consumer equipment and also to enhance the overall performance of the system. The main effect caused by these problems is the production of harmonics. This results in the overheating of the equipment, insulation failure and over speeding of induction motors, etc. The solution for eliminating these problems is to filter the harmonics from the system. For this purpose, there are many filter topologies present within the paper. A hybrid filter has been studied in this paper which is a combination of series active filter and shunt passive filter. This paper presents the control strategy to regulate the filter in such a way that the harmonics are reduced. The proposed control strategy is simulated in MATLAB SIMULINK and therefore the results are presented.

\section{INTRODUCTION}

Electrical energy is the most effective and popular sort of energy, therefore modern society depends on the electrical supply. Life can't be imagined without electricity. At an equivalent time, the standard of the electrical power supply plays an important role in the efficient functioning of user equipment. The term power quality became most prominent within both the power sector and the electrical power supply company, therefore the endusers are concerned about it [1]. The standard of power delivered to the consumers depends on the voltage and frequency ranges. If there is any deviation within the voltage and frequency of the electrical power delivered from that of the standard values then the quality of power delivered is affected. Nowadays with the advancement in technology, there is a drastic improvement within semiconductor devices. With this development and advantages, the semi-conductor devices got a permanent place within the power sector helping to ease the control of the overall system. Moreover, in an electrical power system, most of the loads are semiconductor-based equipment. But semiconducting devices are non-linear and draw non-linear current from the source. And semiconductor devices are also involved in power conversion, which can be either AC to DC or DC to AC. This power conversion contains a lot of switching operations which can introduce discontinuity within the current. This discontinuity and nonlinearity produce harmonics in the power system which ultimately affects the quality of power delivered to the user. So to maintain the quality of power delivered, the harmonics should be eliminated. Thus, a device named filter is employed which eliminates the harmonics also filters are used to remove the problems caused by harmonics. There are several filter topologies such as active, passive, and hybrid. Traditionally, passive filters are used, but they depend heavily on system parameters. They also have resonance problems with system impedance and are suitable for filtering out harmonics at a particular frequency. Therefore, to overcome the problems of passive filters, active filters are used, but it is found that active filters are facing some drawbacks when used to improve power quality such as high converter ratings are required, high cost as compared to passive filter, larger size, and increased losses. Therefore, to overcome these shortcomings, a hybrid power filter is proposed which is a combination of active and passive filters [3]. This paper discusses how combining both active and passive filters is an economical solution for improving power quality. The theory proposed in this paper has been validated by simulating it in a MATLAB SIMULINK environment. The proposed control strategy is simulated for unbalanced load conditions.

\section{POWER QUALITY}

Power quality is usually defined as the ability of the power grid to supply clean and steady power flows in the form of a consistently available power supply. Electric current must have a pure sinusoidal wave form and must remain within specified voltage and frequency tolerances.

\subsection{Power Quality Problems}

The quality of power is affected when there is any variation in the voltage, current or frequency [6]. The common problems that affect the sensitivity of the equipment are - power surges, transients, frequency variation, electrical line noise, brownouts or blackouts, power system faults and improper grounding affect. The main effect caused by these problems is the production of harmonics. The presence of harmonics degrades the power quality and may damage the end user equipment. These harmonics causes the heating of underground cables, insulation failure, reduces the lifespan of the equipment, increases the losses etc.

\subsection{Solutions to Power Quality Problems}

The most effective solution to enhance the power quality is the use of filters to reduce the harmonics. The fundamental idea of employing a filter is shown in Fig. 2.1, where the filter injects a compensating current that compensates the harmonics in load current. There are different filter topologies within the literature such as- 
ICRDET-2021, February 26-27, 2021, AICE, Jaipur, India

International Journal of Technical Research \& Science (Special Issue) ISSN No.:2454-2024 (online)

active, passive, hybrid. The passive power filters are used to filter a specific order harmonics and has the problem of parallel resonance. Another solution is the use of Active Power Filter (APF). There are different kinds of APF like series APF, shunt APF. The shunt APF is expensive and is not used for large systems. The series APF works as a harmonic isolator which reduces the negative-sequence voltage [2]. There is another filter topology which is a combination of passive filter and APF referred as Hybrid Filter.

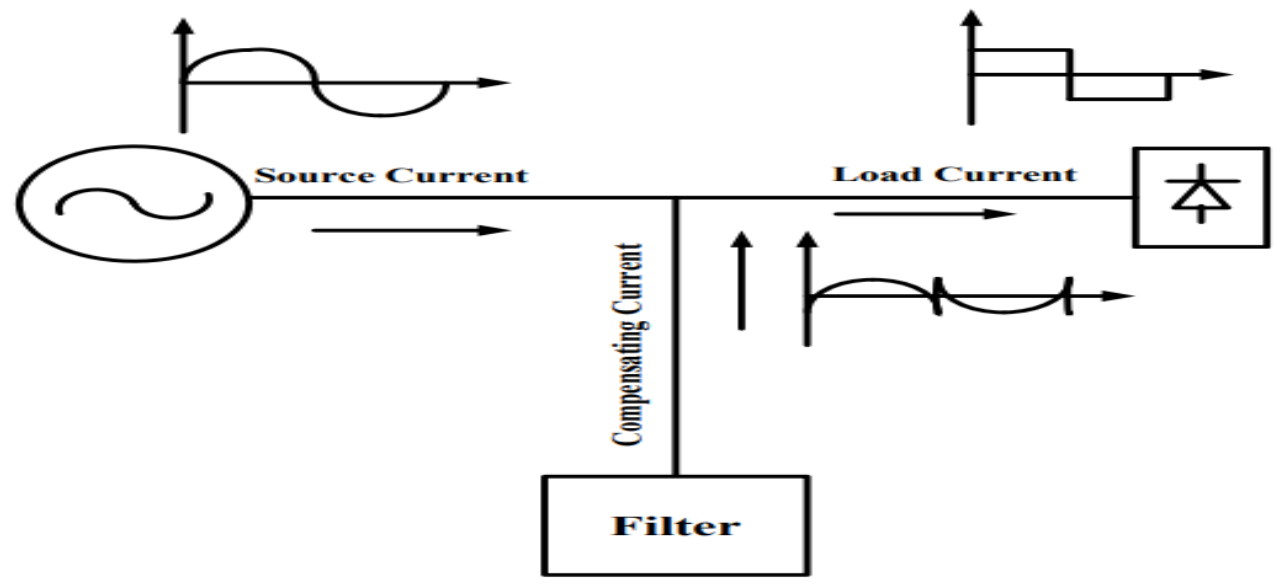

\section{FILTER CLASSIFICATION}

Fig. 2.1 Basic Operation of Filter

Filters are classified into three basic types. They are active filter, passive filter and hybrid filter. Each type has its own sub classification. Fig. 3.1 shows the detailed classification of the filters.

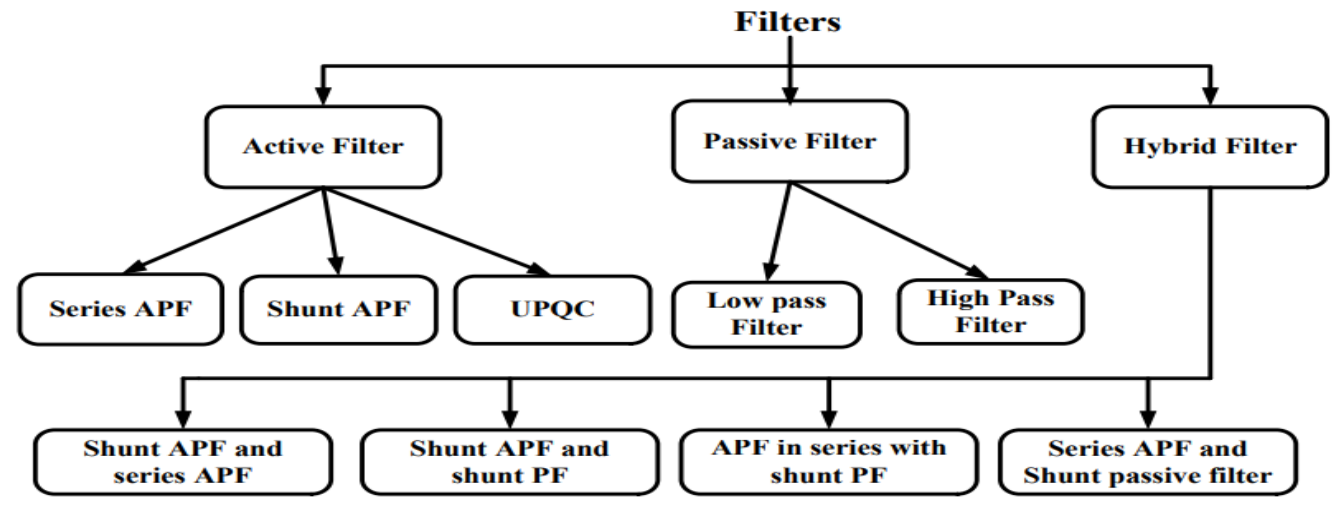

Fig. 3.1 Classification of Filters

\subsection{Passive Filter}

These filters contain passive elements like- capacitor, inductor and resistor. These filters are mostly used because of their low cost and ease of control. Passive filters provide reactive power in addition to filtering out harmonics. The performance of these filters depends on the system impedance. These filters are again classified into two types- low pass and high pass. But there are some disadvantages with passive filter, like - the filter characteristics has a strong dependence on the system impedance, the possibility of overload in the passive filter due to the harmonic current circulation generating from power electronic loads, the change of the load impedance can detune the filter, so it is not suitable for variable loads. The problem of series and/or parallel resonances can be originated which causes unstable operation, limited operation, that is used to eliminate either a particular order or fewer harmonics and component aging. Due to these disadvantages, the passive filters cannot provide an effective solution to enhance the quality of the power system. Thus, active power filters are employed to overcome these drawbacks.

\subsection{Active Filter}

To overcome the drawback of passive filter, active compensation known as Active Power Filter (APF) is used. APF is a voltage source inverter (VSI) that injects compensating current or voltage depending on the network configuration. It was proposed around 1970. But the recent advancement in power electronics technology [2], along with the theory of instantaneous active and reactive power which was presented in 1983, APFs are an upto-date solution with fast switching devices, low power loss, and fast digital processing equipment at an affordable cost. Depending on the circuit configuration and function, APF's are divided into three types - shunt active power filter, series active power filter, and unified power quality conditioner (UPQC).

\subsection{Hybrid Filter}

Active power filters are a better solution for improving power quality but they require a higher converter rating. So to overcome this drawback, hybrid filters are designed. The hybrid filter is a combination of both active and 
ICRDET-2021, February 26-27, 2021, AICE, Jaipur, India

International Journal of Technical Research \& Science (Special Issue) ISSN No.:2454-2024 (online)

passive filters. These filters have the advantage of both active and passive filters. There are different types of hybrid filters depending on the circuit combination and arrangement. They are -

$>$ Shunt APF and Series APF

$>$ Shunt APF and Shunt Passive Filter

$>$ APF in series with Shunt Passive Filter

$>$ Series APF with Shunt Passive Filter

\section{DESIGN OF HYBRID FILTER}

Filters are used to reduce the harmonics and improve the power quality. The filter attached to the system must be effectively controlled so that its response characteristics are desired. Among all the different available filter configurations, a hybrid power filter with series APF and a parallel passive filter is used in this paper. The control circuit of the series-connected APF is designed in such a way that the voltage injected by the APF, which compensates harmonics and also enhances the performance of the shunt-connected passive filter. The control strategy of the hybrid power filter is explained in detail in this paper. The series APF is realized as a voltage source inverter (VSI) used to improve power quality [8]. It can be a three-phase VSI or three single-phase VSI can also be used. VSI is connected in series with the source impedance through a coupling transformer. The circuit diagram is shown in Fig. 4.1. A capacitor is used at the input of the VSI to provide constant input voltage to VSI. A passive filter is also connected at the PCC (Point of Common Coupling). This filter is used to eliminate higher-order harmonics [9] [10]. In certain cases, there may be two or more LC branches used to eliminate specific order harmonics (especially 5th and 7th). Also, a ripple filter is used in series with VSI. The filter parameters are selected in such a way that they do not exceed the transformer burden. Thus, with an efficient control strategy, APF compensates for voltage imbalance and distortion. The control strategy is designed in such a way that the series APF acts as a balanced resistive load on the overall system with the passive filter. In a four-wire system, the harmonic currents circulating in the neutral wire are also reduced due to the series APF.

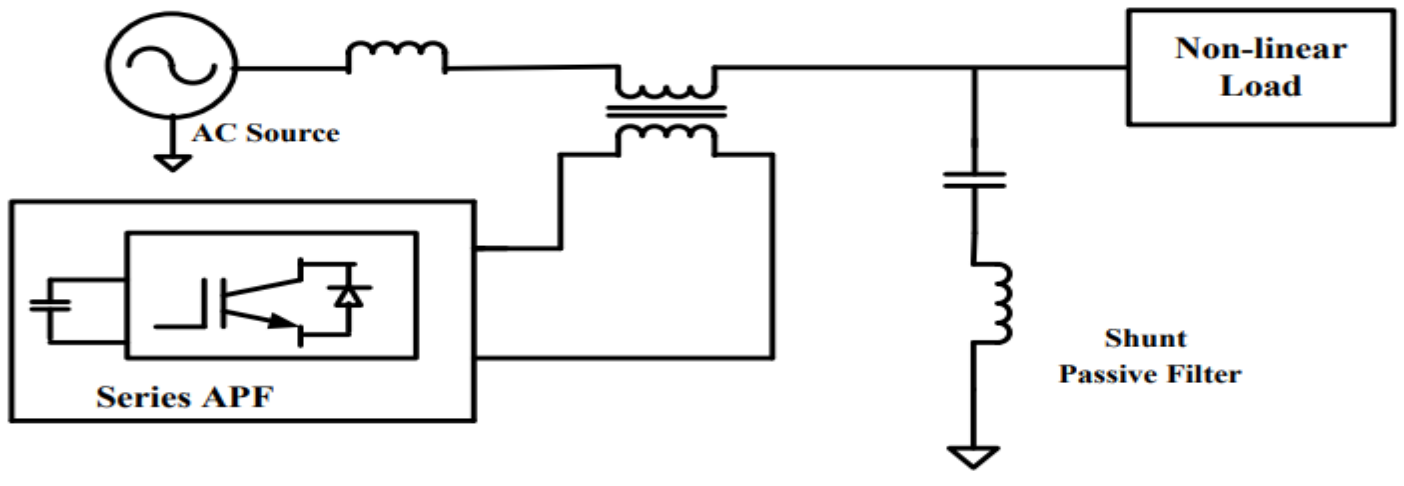

\section{SIMULATION AND RESULTS}

Fig. 4.1 Basic configuration of hybrid filter

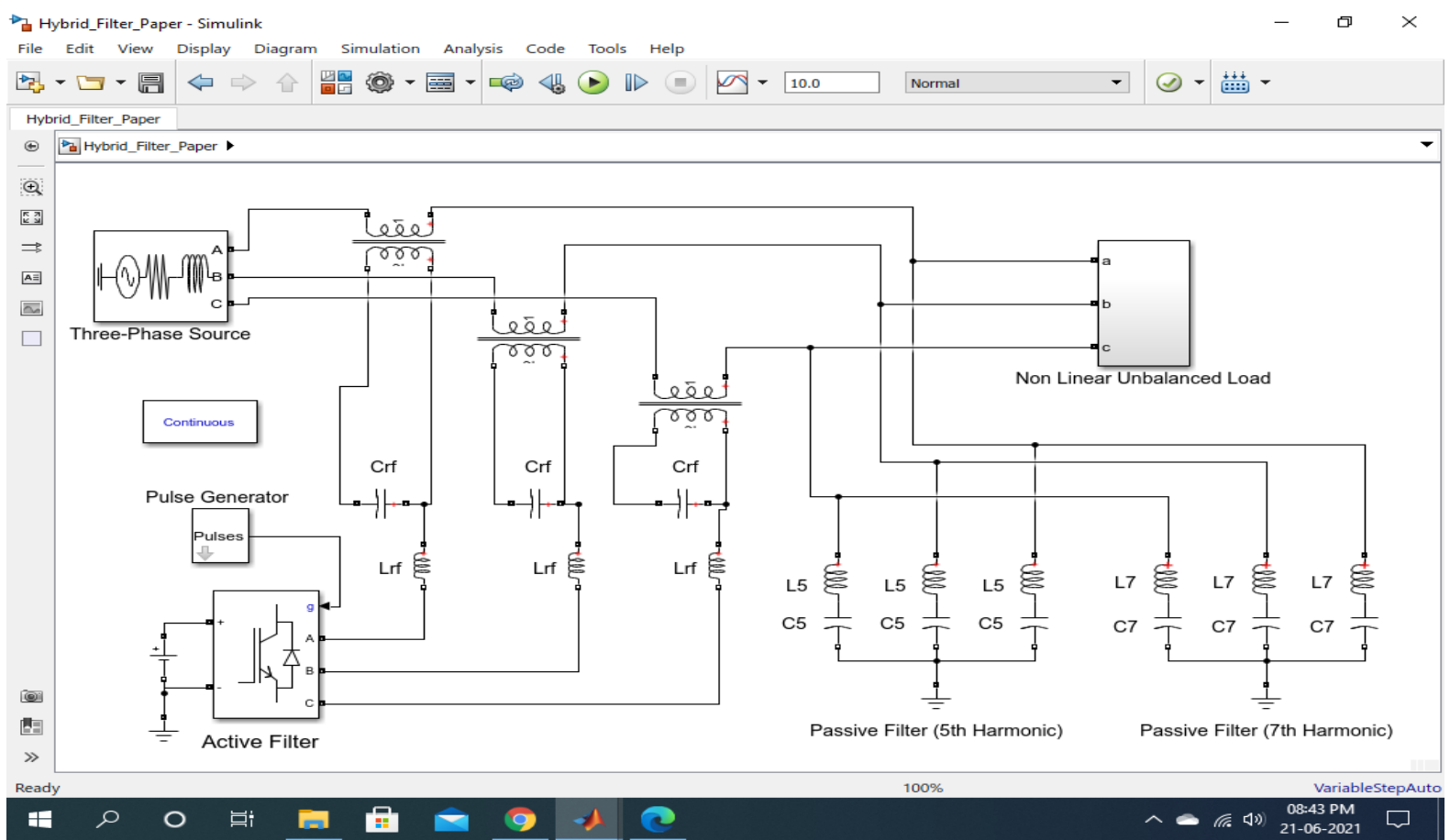

Fig.-5.1 Simulation Diagram with non-linear unbalanced load

The proposed control strategy is simulated with a non-linear unbalanced load shown in Fig 5.1 and the performance of the system is observed. The system data is given in Table - 5.1.

DOI Number: https://doi.org/10.30780/specialissue-ICRDET-2021/006 
ICRDET-2021, February 26-27, 2021, AICE, Jaipur, India

International Journal of Technical Research \& Science (Special Issue) ISSN No.:2454-2024 (online)

Table 5.1 System Parameters

\begin{tabular}{|c|c|}
\hline System Parameter & Value \\
\hline Voltage & $100 \mathrm{~V}$ \\
\hline Switching Frequency & $20 \mathrm{KHz}$ \\
\hline Source Inductance & $5.8 \mathrm{mH}$ \\
\hline Source Resistance & $3.6 \Omega$ \\
\hline Turns Ratio of Coupling Transformer & $1: 1$ \\
\hline
\end{tabular}

The series APF is connected through a coupling transformer whose turn's ratio is 1:1. A passive filter is connected at PCC to eliminate fifth and seventh-order harmonics. Ripple filter is also connected at the output of the VSI (Voltage Source Inverter). The values of these filters are given in Table - 5.2.

Table 5.2 Filter Parameters

\begin{tabular}{|c|c|}
\hline Filter Parameter & Value \\
\hline $\mathrm{L}_{5}$ & $13.5 \mathrm{mH}$ \\
\hline $\mathrm{C}_{5}$ & $30 \mu \mathrm{F}$ \\
\hline $\mathrm{L}_{7}$ & $6.75 \mathrm{mH}$ \\
\hline $\mathrm{C}_{7}$ & $30 \mu \mathrm{F}$ \\
\hline $\mathrm{L}_{\mathrm{rf}}$ & $13.5 \mathrm{mH}$ \\
\hline $\mathrm{C}_{\mathrm{rf}}$ & $50 \mu \mathrm{F}$ \\
\hline
\end{tabular}

The power system may experience unbalanced load conditions sometimes. Thus, the behavior of the proposed control strategy is analyzed by simulating it under unbalanced loading conditions. Here an unbalanced load is created by connecting three single-phase uncontrolled rectifiers with capacitor and resistor in parallel on the DC side. The load values are given in Table -5.3 .

Table 5.3 Load Values

\begin{tabular}{|c|c|c|}
\hline Phase & C & R \\
\hline Phase a & $2200 \mu \mathrm{F}$ & $16.67 \Omega$ \\
\hline Phase b & $2200 \mu \mathrm{F}$ & $25 \Omega$ \\
\hline Phase c & $2200 \mu \mathrm{F}$ & $50 \Omega$ \\
\hline
\end{tabular}

The filter impedance should be less than the system impedance for effective filtering. The simulation is carried out under two conditions- with the actual system parameters and by increasing the impedance of the LC filter more than the source impedance.

\subsection{With the Actual System Parameters}

The proposed control strategy is simulated with actual system parameters given in Table-5.2, filter parameters given in Table-5.3 with unbalanced load values given in Table-5.4. Fig. 5.2 shows the source current waveform without any compensation. From the waveform, it is clear that there many harmonics present in the system. Fig.5.4 shows the source current waveform with a passive filter. Thus, to reduce these harmonics, APF is connected, and then the source current is changed as shown in Fig. 5.6. So it is clear from Fig. 5.6 that the three-phase source

DOI Number: https://doi.org/10.30780/specialissue-ICRDET-2021/006 
ICRDET-2021, February 26-27, 2021, AICE, Jaipur, India

International Journal of Technical Research \& Science (Special Issue) ISSN No.:2454-2024 (online) current is almost sinusoidal. Hence, the system performance is enhanced by connecting the APF under unbalanced load conditions.

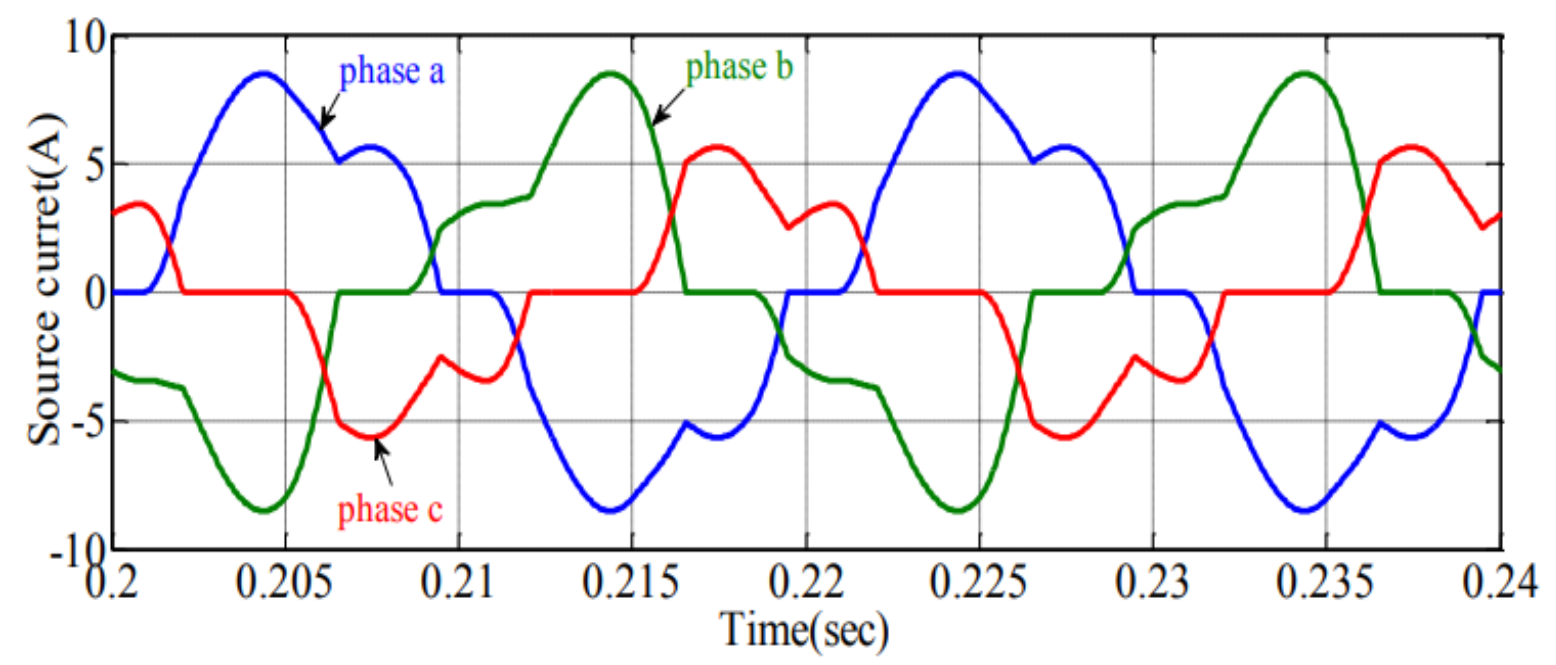

Fig.-5.2 Source Current without any Compensation

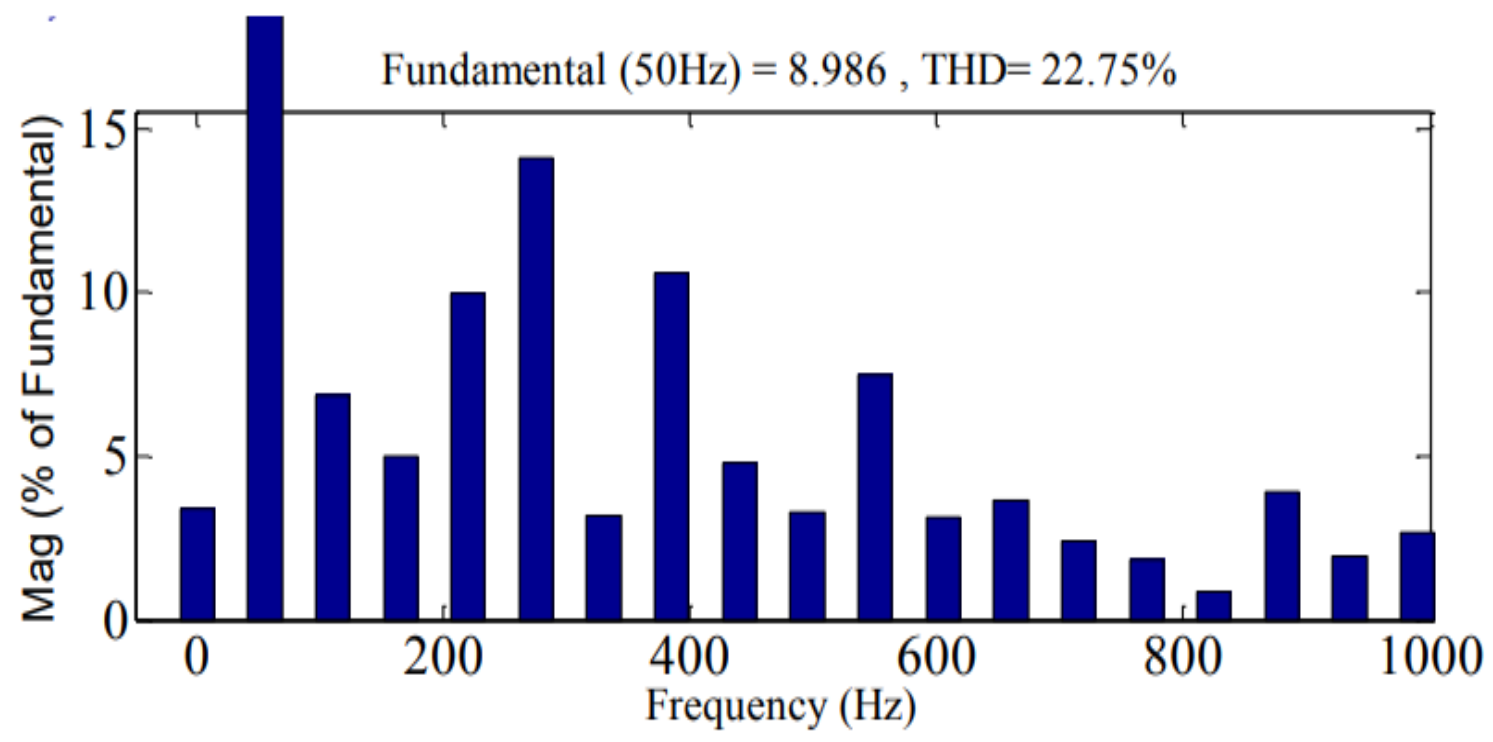

Fig.-5.3 THD of Source Current without any Compensation

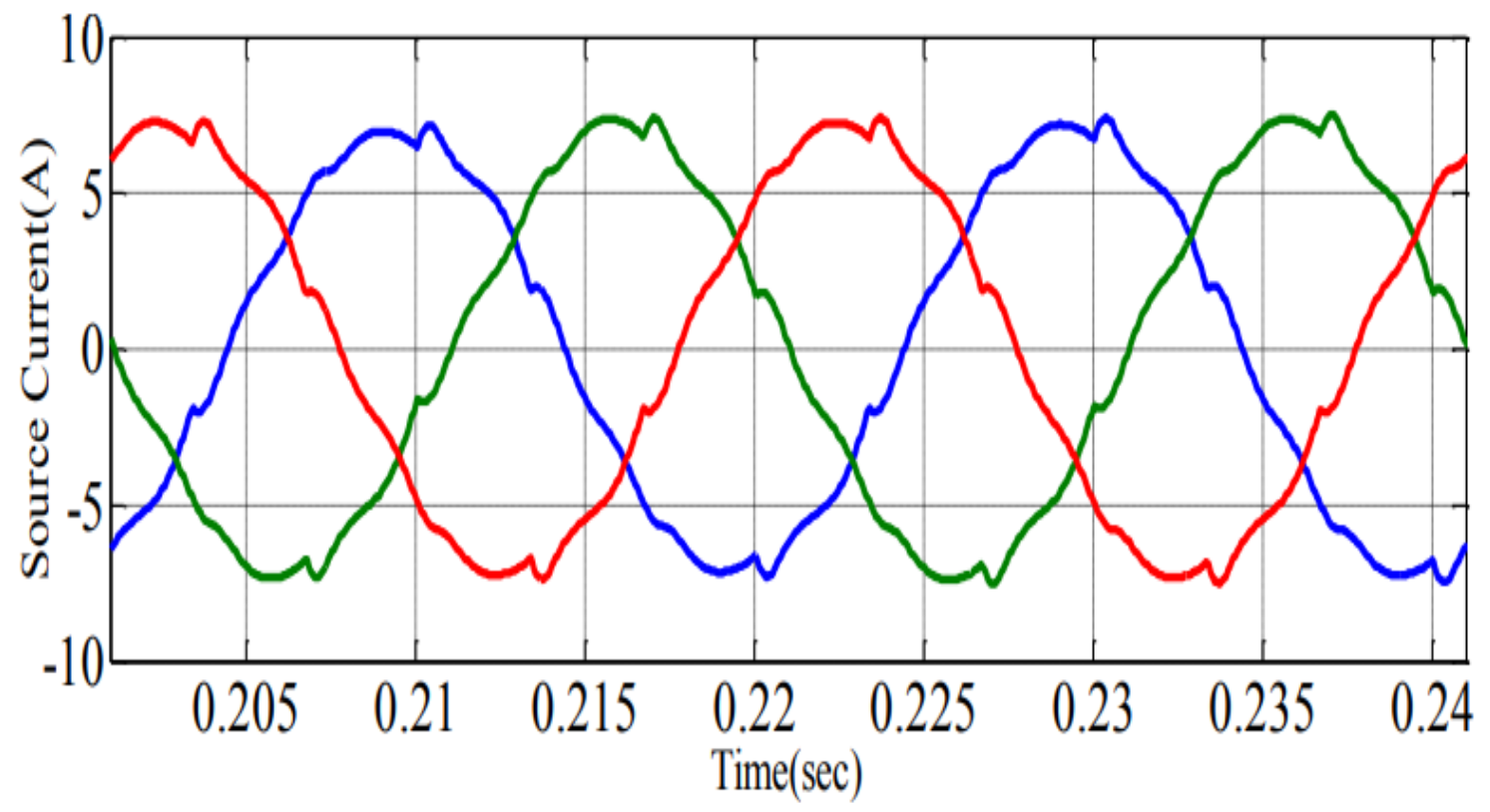

Fig.-5.4 Source Current with Passive filter

DOI Number: https://doi.org/10.30780/specialissue-ICRDET-2021/006

pg. 25

Paper Id: IJTRS-ICRDET-21-006

@2017, IJTRS All Right Reserved, www.ijtrs.com 
ICRDET-2021, February 26-27, 2021, AICE, Jaipur, India

International Journal of Technical Research \& Science (Special Issue) ISSN No.:2454-2024 (online)

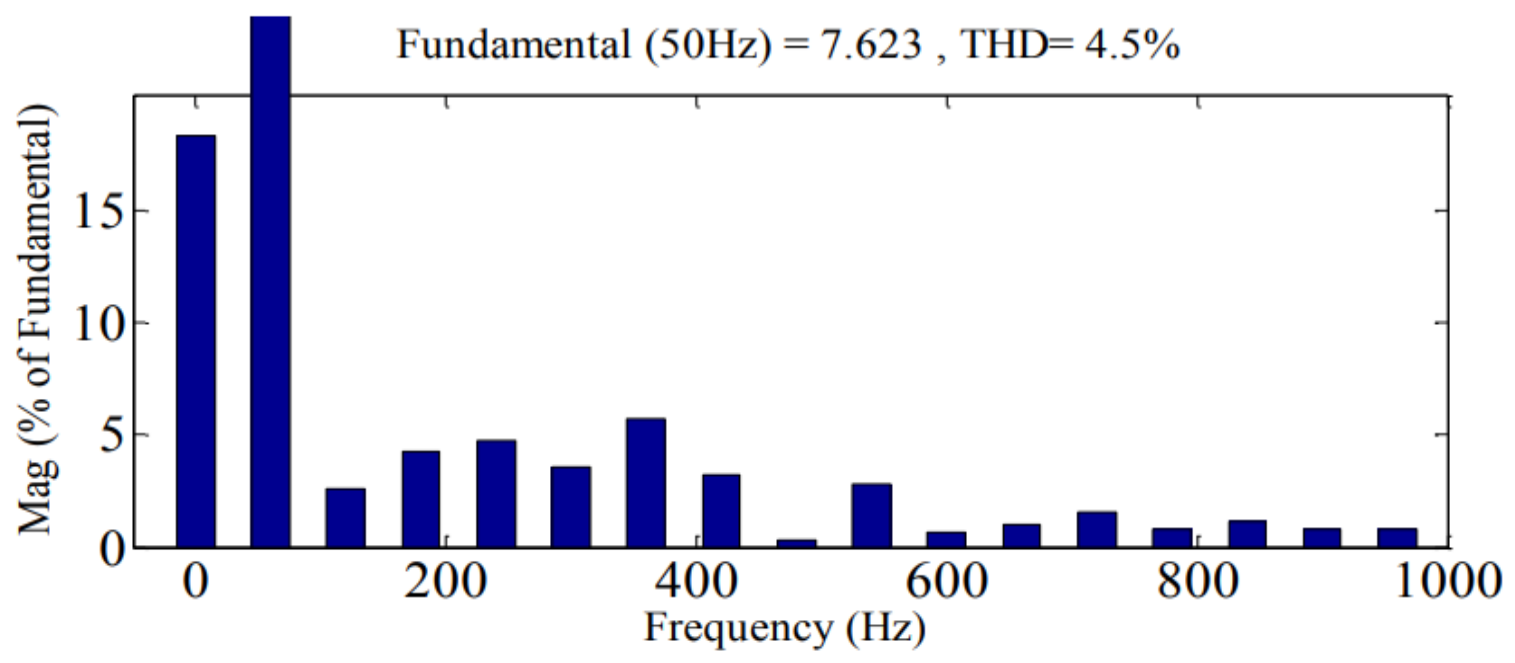

Fig.-5.5 THD of Source Current with Passive filter

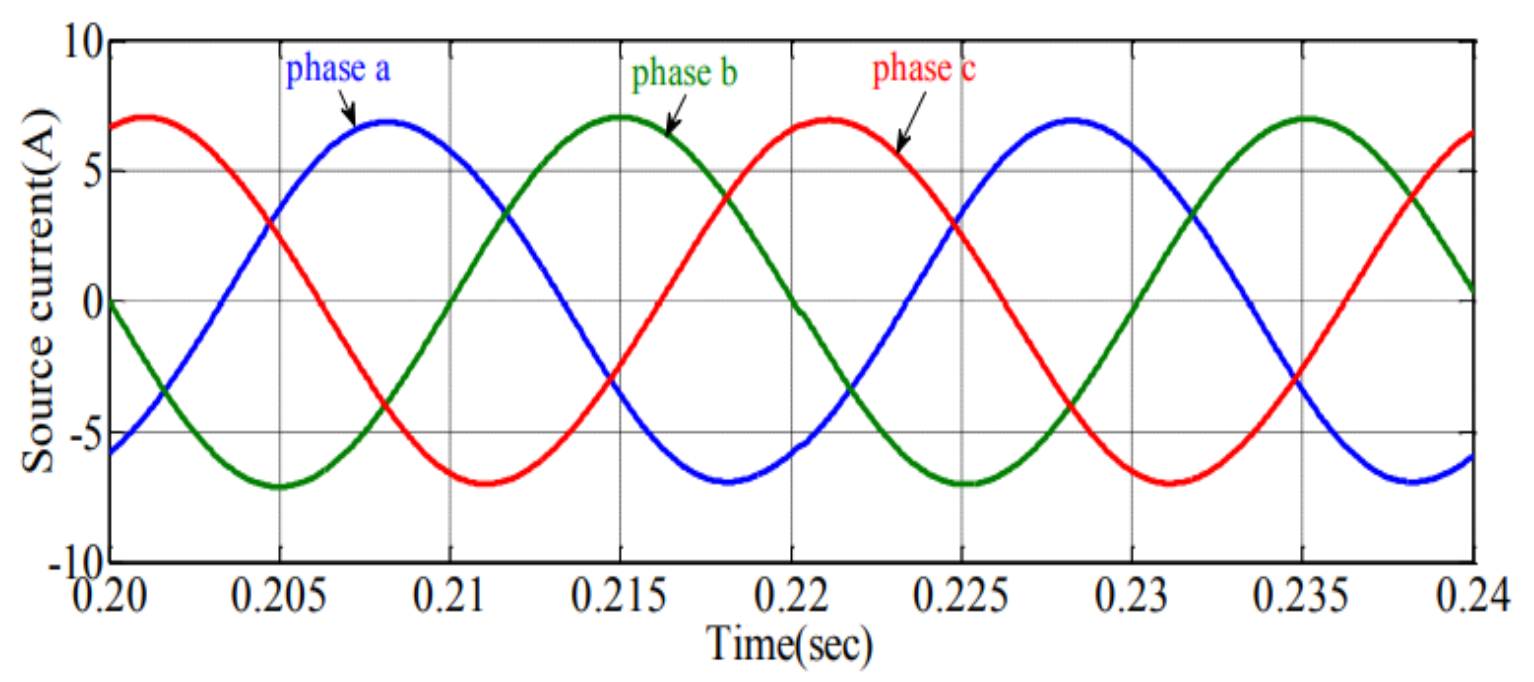

Fig.-5.6 Source Current with Hybrid filter

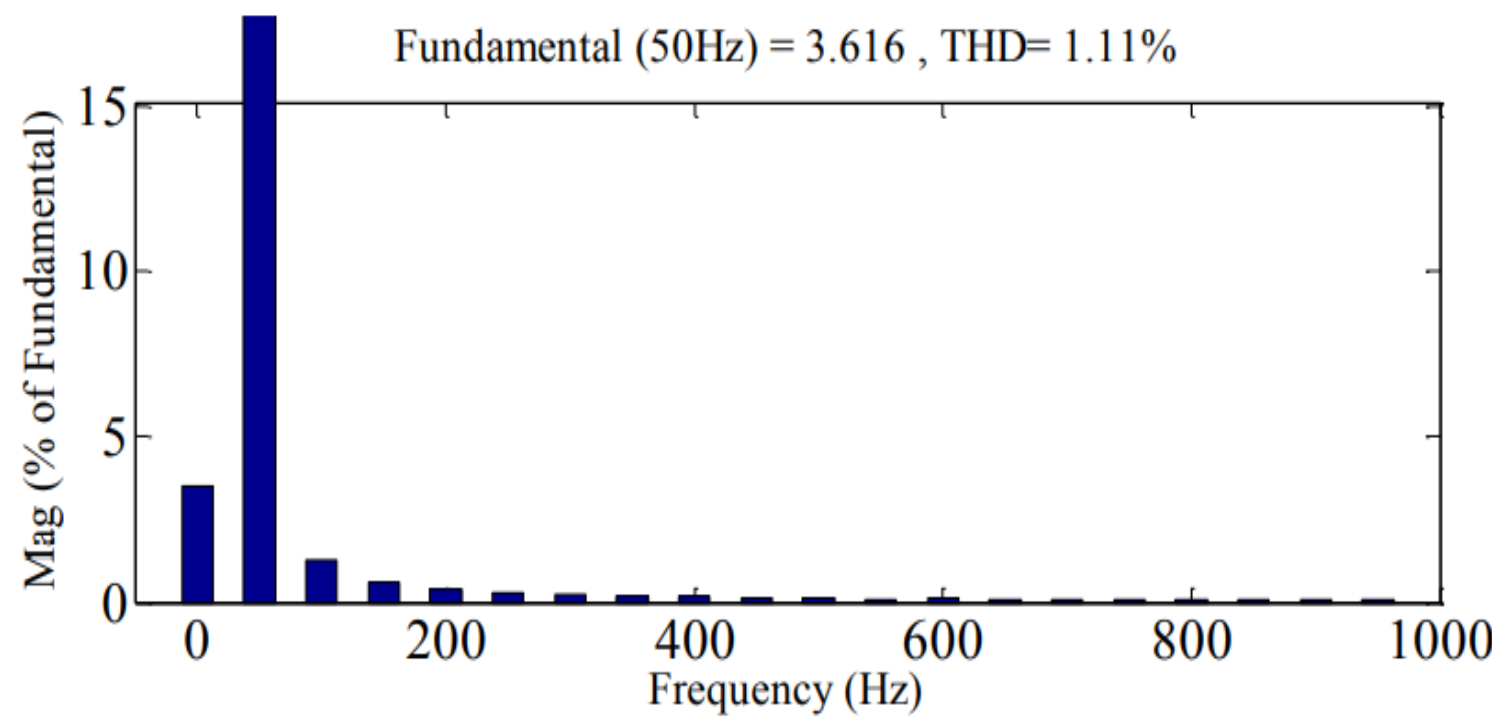

Fig.-5.7 THD of Source Current with Hybrid filter

5.2 When the Source Impedance is Changed

The source impedance of the system is reduced from its previous value given in Table-5.1 and the new values are$\mathrm{Ls}=2.34 \mathrm{mH}$ and $\mathrm{Rs}=1.3 \Omega$. The simulation results are presented in Fig. 5.8. As in balanced load conditions, even under unbalance conditions the system behavior is affected if the source impedance is less than the filter impedance. So the filter design should be done in such a way that the filter impedance is always less than the source impedance.

DOI Number: https://doi.org/10.30780/specialissue-ICRDET-2021/006

pg. 26

Paper Id: IJTRS-ICRDET-21-006

@ 2017, IJTRS All Right Reserved, www.ijtrs.com 
ICRDET-2021, February 26-27, 2021, AICE, Jaipur, India

International Journal of Technical Research \& Science (Special Issue) ISSN No.:2454-2024 (online)

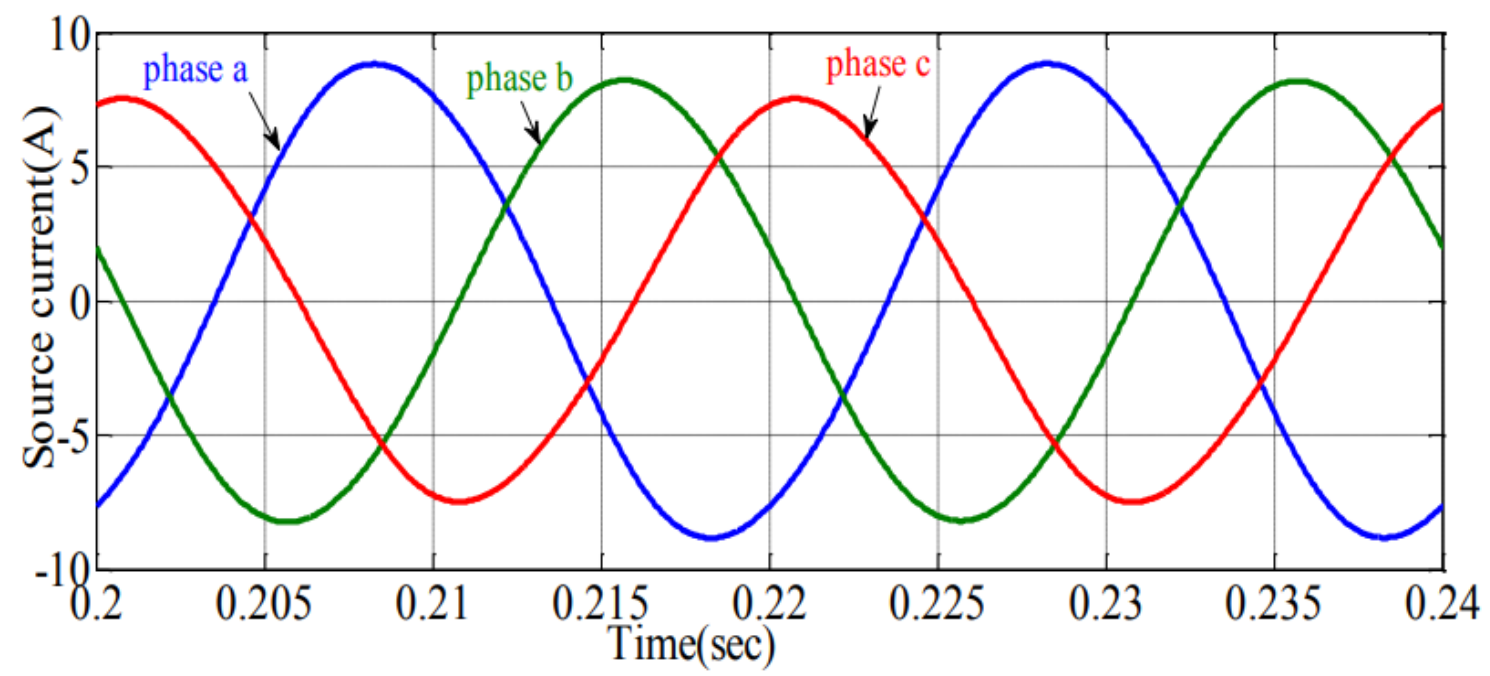

Fig.-5.8 Source Current with Hybrid filter when Source impedance is changed

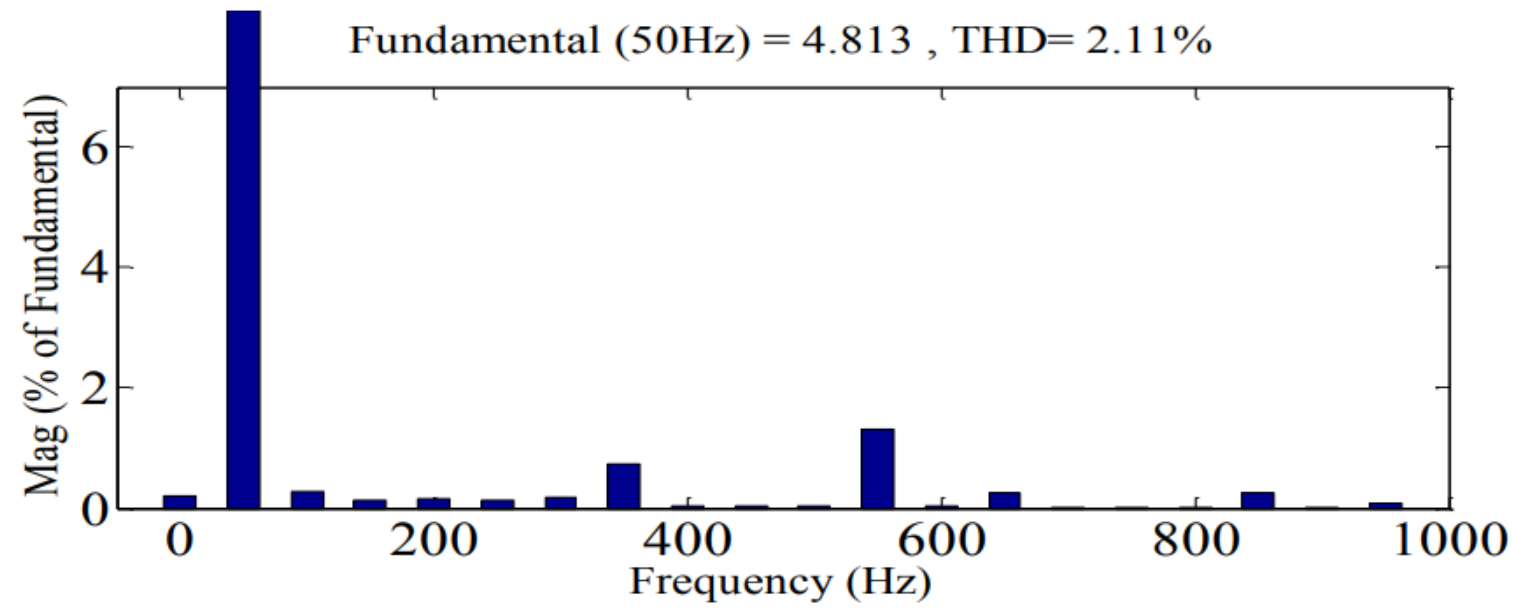

Fig.-5.9 THD of Source Current with Hybrid filter when Source impedance is changed 5.3 Comparative Study under Unbalanced Load Condition

A comparative study of the three-phase source current THD during unbalanced load at various operating conditions, presented in Table-5.4. It is clear from these results that the proposed control strategy works optimally in almost all operating conditions and thus helps in improving the quality of electrical power delivered to the enduser.

Table 5.4 Comparison of source current THD under unbalanced load

\begin{tabular}{|l|c|c|c|c|}
\hline \multirow{2}{*}{ CONDITIONS } & \multicolumn{2}{|c|}{ THD } & \multicolumn{2}{c|}{ POWER } \\
FACTOR
\end{tabular}


ICRDET-2021, February 26-27, 2021, AICE, Jaipur, India

International Journal of Technical Research \& Science (Special Issue) ISSN No.:2454-2024 (online)

\section{REFERENCES}

[1]. Awad, H.; Bollen, M. H J, "Power electronics for power quality improvements," Industrial Electronics, 2003. ISIE '03. 2003 IEEE International Symposium on, vol.2, no., pp.1129,1136 vol. 2, 9-11 June 2003 doi: 10.1109/ISIE.2003.1267983

[2]. Singh, Bhim; Al-Haddad, K.; Chandra, A., "A review of active filters for power quality improvement," Industrial Electronics, IEEE Transactions on, vol.46, no.5, pp.960,971, Oct 1999 doi: 10.1109/41.793345

[3]. Rivas, D.; Moran, L.; Dixon, J.W.; Espinoza, J.R., "Improving passive filter compensation performance with active techniques," Industrial Electronics, IEEE Transactions on , vol.50, no.1, pp.161,170, Feb. 2003 doi: 10.1109/TIE.2002.807658

[4]. Herrera, R.S.; Salmeron, P., "Instantaneous Reactive Power Theory: A Comparative Evaluation of Different Formulations," Power Delivery, IEEE Transactions on, vol.22, no.1, pp.595,604, Jan. 2007 doi: 10.1109/TPWRD.2006.881468

[5]. Salmeron, P.; Litran, S.P., "Improvement of the Electric Power Quality Using Series Active and Shunt Passive Filters," Power Delivery, IEEE Transactions, vol.25, no.2, pp.1058,1067, April 2010 doi: 10.1109/TPWRD.2009.2034902

[6]. M H J Bollen, Understanding Po11 er Quality Problenis Voltage Sags andlnterruptions, New York, IEEE Press, 1999.

[7]. Axente, N. G. Jayanti, M.Basu, and M. F. Conlon, "A 12 kVA DSPcontrolled laboratory prototype UPQC capable of mitigating unbalance in source voltage and load current," IEEE Trans. Power Electron. , vol. 25, no. 6, pp. 1471-1479, Jun. 2010.

[8]. H. Akagi, “Active harmonic filters,” Proc. IEEE, vol. 93, no. 12, pp. 2128-2141, Dec. 2005.

[9]. B. Singh, K. Al-Haddad, and A. Chandra, “A review of active filters for power quality improvement," IEEE Trans. Ind. Electron., vol. 46, no. 5, pp. 960-971, Oct. 1999.

[10]. J. W. Dixon, G. Venegas, and L. A. Moran, "A series active power filter based on a sinusoidal currentcontrolled voltage-source inverter,” IEEETrans. Ind. Electron., vol. 44, no. 5, pp. 612-620, Oct. 1997.

[11]. H. Yang and S. Ren, "A practical series-shunt hybrid active power filter based on fundamental magnetic potential self-balance," IEEE Trans.Power Del., vol. 23, no. 4, pp. 2089-2096, Oct. 2008.

[12]. A. Luo, Z. Shuai, W. Zhu, R. Fan, and C. Tu, "Development of hybrid active power filter based on the adaptive fuzzy dividing frequency-control method," IEEE Trans Power Del., vol. 24, no. 1, pp. 424-432, Jan. 2009.

[13]. Kneschke, T., "Distortion and power factor of nonlinear loads," Power Engineering Society Summer Meeting, 1999. IEEE, vol.1, no., pp.457,462 vol.1, 18-22 Jul 1999 doi: 10.1109/PESS.1999.784391

[14]. F. Z. Peng and D. J. Adams, "Harmonics sources and filtering approaches," in Proc. Industry Applications Conf., Oct. 1999, vol. 1, pp. 448-455.

[15]. H. Yang and S. Ren, "A practical series-shunt hybrid active power filter based on fundamental magnetic potential self-balance," IEEE Trans.Power Del., vol. 23, no. 4, pp. 2089-2096, Oct. 2008.

[16]. A. Luo, Z. Shuai, W. Zhu, R. Fan, and C. Tu, "Development of hybrid active power filter based on the adaptive fuzzy dividing frequency-control method," IEEE Trans Power Del., vol. 24, no. 1, pp. 424-432, Jan. 2009.

[17]. F. Z. Peng, H. Akagi, and A. Nabae, "A new approach to harmonic compensation in power systems-a combined system of shunt passive and series active filters," IEEE Trans. Ind. Appl., vol. 26, no. 6, pp. 983990, Nov./Dec. 1990.

[18]. H. Zhong, P. Chen, Z. Lu, Z. Qian, and H. Ma, "Three phase fourwire series hybrid active power filter with fundamental current bypass channel," in Proc. Industrial Electronics Society (IECON), Nov. 2004, vol. 1, pp. 536- 539.

[19]. G.-M. Lee, D.-C. Lee, and J.-K. Seok, "Control of series active power filters compensating for source voltage unbalance and current harmonics," IEEE Trans. Ind. Electron., vol. 51, no. 1, pp. 132-139, Feb. 2004.

[20]. P. Salmerón, R. S. Herrera, and J. R. Vázquez, "Mapping matrices against vectorial frame in the instantaneous reactive power compensation," IET Elect. Power Applic., vol. 1, no. 5, pp. 727-736, Sep. 2007.

[21]. H. Akagi, Y. Kanazawa, and A. Nabae, "Instantaneous reactive power compensators comprising switching devices without energy storage components," IEEE Trans. Ind. Appl., vol. IA-20, no. 3, pp. 625-630, May/Jun. 1984.

[22]. A. Horn, L. A. Pittorino, and J. H. R. Enslin, "Evaluation of active power filter control algorithms under non-sinusoidal and unbalanced conditions," in Proc. 7th Int. Conf. Harmonics and Quality Power, Oct. 1618, 1996, pp. 217-224.

[23]. J. K. Phipps, J.P. Nelson, P. K. Sen, "Power Quality and Harmonic Distortion on Distribution Systems", in IEEE Trans. on Ind. Appl., vol. 30, No 2, March/April 1994, pp. 176-184.

[24]. H. Sasaki and T. Machida, "A new method to eliminate ac harmonic currents by magnetic compensation consideration on basic design”, IEEE Trans. Power Appl. Syst. 90 (5), 20092019 (1971). 